\title{
Foreword to the special issue: NPIA systematic reviews in policing
}

\author{
Charlotte Gill • David B. Wilson • Rachel Tuffin • \\ David Weisburd
}

Published online: 1 October 2014

(C) Springer Science+Business Media Dordrecht 2014

The collection of papers in this Special Issue came about as a result of the most significant funding award to date dedicated to obtaining a broad perspective of "what works" in the field of policing. In 2009, the National Policing Improvement Agency (NPIA) in the United Kingdom, under the leadership of former Thames Valley Police Chief Constable Peter Neyroud, provided over US\$600,000 to the Campbell Collaboration Crime and Justice Group (CCJG), via the Center for Evidence-Based Crime Policy at George Mason University where CCJG's editorial team is based, to develop a portfolio of systematic reviews on policing topics. In total, 11 systematic searches and reviews were completed and peer reviewed under this program between 2009 and 2013. ${ }^{1}$ This Special Issue contains a selection of these reviews not published elsewhere, as well as several papers on lessons learned from the funded projects and areas for future development.

The impact of these reviews on the field of policing has been significant. This Special Issue begins with a case study by Telep and Weisburd, which documents the history and development of the CCJG-NPIA systematic review program and its impact on the production of CCJG reviews and evidence-based policing. In addition to more than doubling the number of systematic reviews on policing topics, the program has made a substantial contribution to reversing the historical belief that the police can do nothing to prevent crime. These systematic reviews show us that a number of policing practices and techniques, both existing and innovative, are in fact effective or promising.

Three systematic reviews presented in this issue (Gill and colleagues; Higginson and Mazerolle; Meissner and colleagues) suggest that police can have a positive impact not

\footnotetext{
${ }^{1}$ The full set of reviews is discussed in detail in Telep and Weisburd, this issue.

C. Gill $(\bowtie) \cdot$ D. B. Wilson • D. Weisburd

Department of Criminology, Law and Society, George Mason University, Fairfax, VA, USA

e-mail: cgill9@gmu.edu

R. Tuffin

College of Policing, London, UK

D. Weisburd

Institute of Criminology, Faculty of Law, Hebrew University, Jerusalem, Israel
} 
only on controlling crime but also on public perception and cooperation. Communityoriented policing may set the scene for longer-term crime control benefits by improving citizens' satisfaction with and perceived legitimacy of the police, while policing strategies with a procedural justice orientation, whether on the street or in the interview room, increase the likelihood of cooperation and can ultimately bring down crime rates. However, an effective police service requires healthy police officers, and the review by Patterson, Chung, and Swan suggests that more research is needed on the identification of and response to police stress.

The NPIA reviews also provide us with further evidence to support the notion that displacement of crime is not inevitable as a result of place-based policing programs. Telep and colleagues extend the analysis of displacement beyond geographicallyfocused police interventions to the larger places, such as police districts and even jurisdictions at which many interventions are directed. In line with prior research on displacement at smaller places, their findings lend more support for a diffusion of crime control benefits, more than displacement, across larger units of geography. Johnson, Guerette and Bowers draw upon these findings as well as their own NPIA-funded review of small-place displacement to summarize what we have learned about displacement so far-and what we have yet to discover.

This issue concludes with Braga and Weisburd's call for more methodologically rigorous research around policing strategies at places, inspired by their NPIA-funded review of focused deterrence programs. Despite the significant jump in the number of systematic reviews on policing thanks to the CCJG-NPIA program, there remains work to be done on developing high-quality primary studies - especially ones that include experimental methods - to strengthen our conclusions about the effectiveness of police work. As Telep and Weisburd discuss in their case study, the National Policing Improvement Agency was disbanded in 2013 as a result of the UK government's efforts to reduce the number of quasi non-governmental organizations. However, its research-related functions were retained and transitioned to the College of Policing, the UK's new professional body for policing, with a key objective to "identify, develop, and promote good practice based on evidence". ${ }^{2}$ The College of Policing's Chief Executive Alex Marshall's commitment to coordinating and expanding the policing research evidence base also suggests the advancement of knowledge about what works in policing is now a more secure endeavor.

Thus, evidence-based policing continues to gain momentum in the UK, as it has in the United States and elsewhere. The College of Policing is now hosting the government's What Works Centre for Crime Reduction, which is synthesizing knowledge from reviews like the ones published here to increase police participation in research and develop dissemination and translation models. The College of Policing research team developed a competitive process similar to the systematic review program partnership with the Campbell Collaboration Crime and Justice Gorup to fund academic partners in collaboration with the Economic and Social Research Council in the UK. Ultimately, the investment in evidence generation that reviews like these embody represents a push toward informed decisionmaking, public accountability, improved collaboration and better value for money in policing-lessons that can be applied around the world.

\footnotetext{
${ }^{2}$ College of Policing website, http://www.college.police.uk/en/19789.htm. Accessed August 1, 2014.
} 
Charlotte Gill is an Assistant Professor in the Department of Criminology, Law and Society and Deputy Director of the Center for Evidence-Based Crime Policy at George Mason University. She is the current coeditor and former managing editor of the Campbell Collaboration Crime and Justice Group.

David B. Wilson is Professor and Chair, Department of Criminology, Law and Society at George Mason University. He is co-chair of the Campbell Collaboration Crime and Justice Group steering committee and the group's co-editor, and is also a member of the overall Campbell Collaboration Steering Group.

Rachel Tuffin is Head of Research, Analysis and Information at the UK College of Policing and previously held the position of Head of Research at the National Policing Improvement Agency. In 2013 she was awarded an Order of the British Empire (OBE) for her services to evidence-based policing.

David Weisburd is Distinguished Professor in the Department of Criminology, Law and Society and Executive Director of the Center for Evidence-Based Crime Policy at George Mason University. He holds a joint appointment as the Walter E. Meyer Professor of Law and Criminal Justice at the Hebrew University Law School. He is a member and former co-chair of the Campbell Collaboration Crime and Justice Group Steering Committee. 